\title{
Erratum to: Biophotonics
}

\section{Erratum to: \\ G. Keiser, Biophotonics, Graduate Texts in Physics, DOI 10.1007/978-981-10-0945-7}

The subjected book was inadvertently published without including the following typo errors in some of the chapters. The erratum book and the chapters are updated.

The typo errors are:

Page 86: The last part of Problem 3.7 should be “...V = 3.59."

Page 86: In Problem 3.11 the first line should read: " $n_{\text {eff }}=1.479$ and $\Lambda=523 \mathrm{~nm}$ at $20{ }^{\circ} \mathrm{C}$."

Page 115: Problem 4.1 should read: "...show that the irradiance is $3.18 \mathrm{~W} / \mathrm{cm}^{2}$." Page 116: In Problem 4.4 "Table 5.1" should be "Table 4.1."

Page 143: The last part of Problem 5.3 should be "...1678 nm."

Page 166: Eq. (6.17) should be

$$
\mathrm{Q}_{\mathrm{s}}=\frac{8 \mathrm{x}^{4}}{3}\left(\frac{\mathrm{n}_{\mathrm{rel}}^{2}-1}{\mathrm{n}_{\mathrm{rel}}^{2}+2}\right)^{2}
$$

Page 192: In Problem 6.10 the parameter $\alpha_{\mathrm{a}}$ should be $\mu_{\mathrm{a}}$.

Page 192: Problem 6.11: The last part should read "show that $\mu_{\mathrm{s}}=9 \mu_{\mathrm{a}}$."

The updated original online version for this book can be found at DOI 10.1007/978-981-10-0945-7

\footnotetext{
G. Keiser $(\bowtie)$

Department of Electrical and Computer Engineering, Boston University, Newton, MA, USA

e-mail: gkeiser@photonicscomm.com 
Page 227: Problem 7.1: The last part of the second sentence should read "reflection loss of $1.1 \mathrm{~dB}$ at a wavelength $\lambda_{1}$, and a transmission loss of $1.1 \mathrm{~dB}$ at a wavelength $\lambda_{2}$."

Page 228: Problem 7.5 should read: "(a) Show that the size of the active area in a bundle with one ring is $0.22 \mathrm{~mm}^{2}$. (b) Show that the ratio of the active area to the total cross sectional area of the bundle is $54 \%$."

Page 228: Problem 7.6 should read: "(a) ... the active area in a bundle with two rings is $1.13 \mathrm{~mm}^{2}$. (b) ... the active area to the total cross sectional area of the bundle is $53 \%$."

Page 228: Problem 7.8 should read: "the variation in the insertion loss when the longitudinal separation changes from $0.020 \mathrm{~mm}$ to $0.025 \mathrm{~mm}$ is 0.21 dB."

Page 256: Problem 8.5 should read: "Show that the depth of field at a wavelength of $650 \mathrm{~nm}$ is $24.5 \mu \mathrm{m}$ and $3.24 \mu \mathrm{m}$..."

Page 287: Problem 9.7 should read: "Figure 9.9 shows a spheroid with the radii of the equatorial and polar axes being $0.3 \mu \mathrm{m}$ and $2.4 \mu \mathrm{m}$, respectively."

Page 287: Problem 9.10 should read: "...the curved cylinder has a length of $550 \mu \mathrm{m}$ and its radius is $\mathrm{a}=0.5 \mathrm{D}_{\text {bottom }}=150 \mu \mathrm{m}$." 